\title{
BMJ Open Quality Improving postpartum care in a large hospital in New Delhi, India
}

\author{
Mona Chopra, ${ }^{1}$ Neerja Arora, ${ }^{2}$ Shailja Sinha, ${ }^{3}$ Silvia Holschneider,${ }^{4}$ Nigel Livesley ${ }^{4}$
}

To cite: Chopra M, Arora N, Sinha S, et al. Improving postpartum care in a large hospital in New Delhi, India.BMJ Open Quality 2018;7:e000423. doi:10.1136/ bmjoq-2018-000423

Received 11 May 2018 Accepted 11 June 2018

\section{Check for updates}

(c) Author(s) (or their employer(s)) 2018. Re-use permitted under CC BY-NC. No commercial re-use. See rights and permissions. Published by BMJ.

${ }^{1}$ IPE Global Limited, New Delhi, India

${ }^{2}$ The Union South East Asia, New Delhi, India

${ }^{3}$ Department of Obestrics and Gynecology, Bhagwan Mahavir Hospital, Delhi, India

${ }^{4}$ Quality and Performance Institute, USAID Applying Science to Strengthen and Improve Systems (ASSIST), University Research Co., LLC, Chevy Chase, Maryland, USA

Correspondence to

Dr Nigel Livesley;

nlivesley@urc-chs.com

\section{ABSTRACT}

Despite recent progress, the maternal mortality ratio (MMR) in India remains high at 174 per 100000 live births. Bhagwan Mahavir Hospital (BMH) is a secondary level hospital in New Delhi. In 2013, five women died in BMH's postpartum ward. In January 2014, a United States Agency for International Development-funded team met with BMH staff to help improve their system for providing postpartum care to prevent maternal deaths. The hospital staff formed a quality improvement (QI) team and, between January and December 2014, collected data, conducted root cause analyses to understand why postpartum women were dying and tested and adapted small-scale changes using plan-do-study-act cycles to delivery safer postpartum care. Changes included reorganising the ward to reduce the time it took nurses to assess women and educating women and their relatives about common danger signs. The changes led to an increase in the number of women who were identified with complications from two out of 1667 deliveries (0.12\%) between January and May 2014 to 74 out of 3336 deliveries (2.2\%) between July and December 2014. There were no deaths on the postpartum ward in 2014 compared with five deaths in 2013 but the reduction was not sustained after the hospital started accepting sick patients from other hospitals in 2015. Ql approaches can improve the efficiency of care and contribute to improved outcomes. Additional strategies are required to sustain improvements.

\section{BACKGROUND}

The sustainable development goals include a commitment to reduce maternal mortality ratio (MMR) to below 70 deaths per 100000 live births by $2030 .{ }^{1}$ A lot is known about which interventions reduce maternal mortality. ${ }^{2} \mathrm{But}$ despite this knowledge, women often do not receive these interventions when needed.

The MMR in India remains high at 174 per 100000 live births (50 times worse than countries with the lowest MMR). ${ }^{4}$ Over the past decade, India has used conditional cash transfers to increase the number of women delivering in health facilities. This has not lead to a concomitant reduction in mortality. ${ }^{5}$ There is an increasing interest in not simply improving access but also improving quality of care.

Bhagwan Mahavir Hospital (BMH) is a secondary care hospital in New Delhi catering to a low-income population. Sixteen doctors and 30 nurses deliver about 6000 babies every year. During a typical shift, two doctors are on duty and deliver an average of five babies. In 2013, 5854 women delivered in the hospital and five women died in the postpartum ward (institutional MMR 85 deaths per 100000 deliveries). Ward staff felt that the deaths occurred because they were not assessing women frequently after delivery. With the help of the United States Agency for International Development Applying Science to Strengthen and Improve Systems Project, the ward formed a quality improvement (QI) team whose aim was to increase the number of assessments and thereby reduce maternal mortality. No patient specific data was collected, and ethics approval was not required.

\section{METHODS OF IMPROVEMENT}

The QI team collected data from the patient records on how often women were assessed after delivery and how many women were identified with complications. They compiled these data weekly. Indian guidelines recommend that providers assess women 11 times in the first 6 hours. ${ }^{6}$ In January 2014, over a 4-week baseline, the team found, they were only assessing women twice.

Initially, the team did not use QI approaches. Instead, they asked the medical superintendent to issue a letter instructing nurses to assess women six times in the first 6 hours. After 1week, data showed that they had met this target. Between February and May 2014, the number of assessments remained above six. However, only two $(0.12 \%)$ of the 1667 women who had delivered in the past 5 months were identified with complications; in 4 of the 5 months no women were identified with complications (figure 1). Both were severely ill when identified. The infrequent identification of women with complications and the late diagnoses suggested that the assessments were not being conducted carefully and complications were being missed. The team modified their initial aim to increase the number of women being identified with complications. 
16

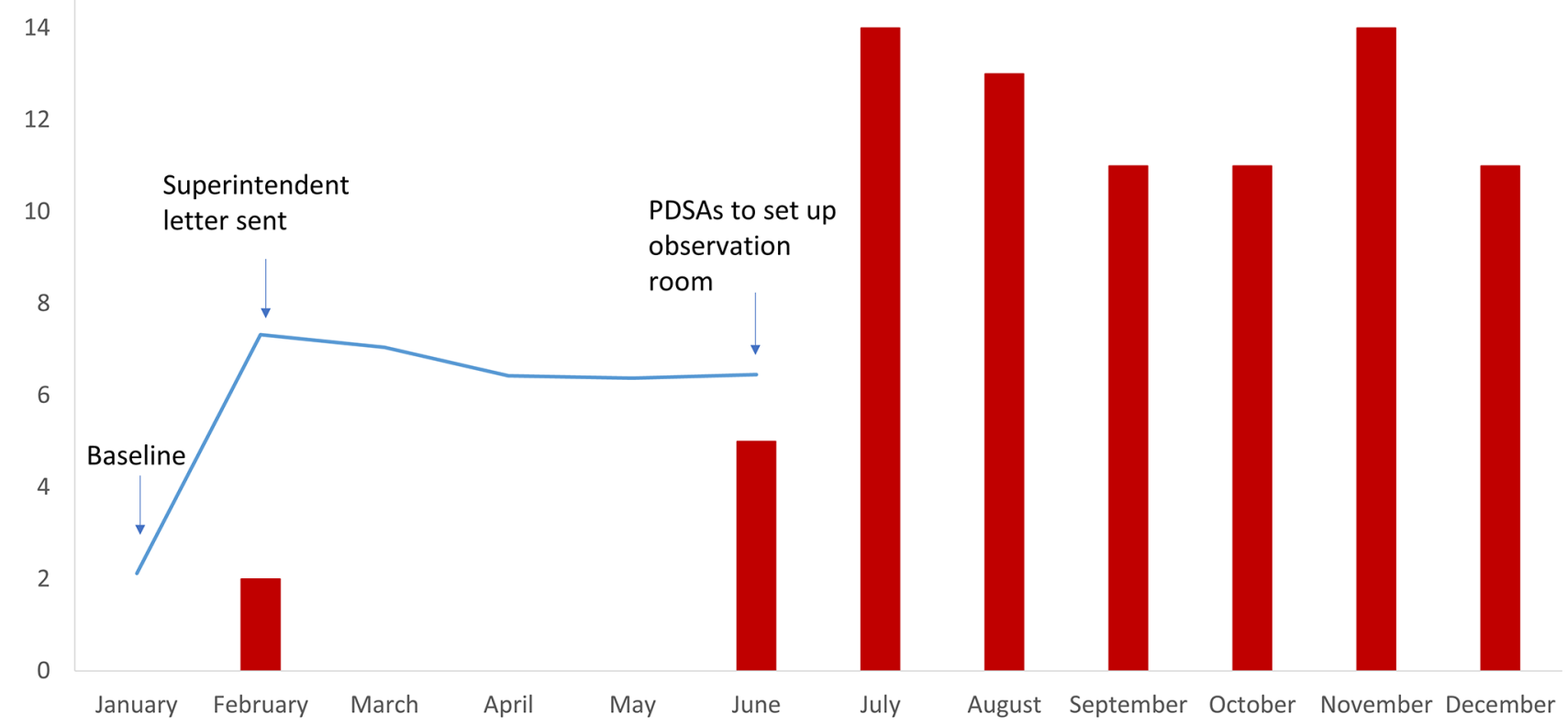

Number of women with danger signs identified in the PNC ward

- Average number of times vitals recorded within first 6 hours of birth

Figure 1 Number of postnatal women monitored and identified with complications in the postnatal care ward (JanuaryDecember 2014). PDSA, plan-do-study-act.

In June, the team decided to start using various QI approaches that they had been taught. ${ }^{7}$ They used flow charts and fishbone diagrams to identify the root causes making it difficult to identify women with complications. Based on this information, the team developed the ideas to address these root causes and used plan-dostudy-act (PDSA) cycles to test and adapt these ideas.

The team identified that nurses were not assessing women carefully because of time constraints. The root cause was that the ward was large and disorganised. Women were placed in different rooms, and assessment equipment was not kept in any standard location. Nurses spent a lot of time looking for equipment and patients. To eliminate this wasted time, the team thought to create an observation room for newly delivered women and to keep the assessment equipment there. The team conducted a half-day long PDSA (PDSA 1-see table 1) cycle to learn how long assessments took. It took $5 \mathrm{~min}$ to assess women in the planned observation room compared with $20 \mathrm{~min}$ when they were located elsewhere. Based on PDSA 1, the team set up the observation room and tested it using a 2 day long PDSA (PDSA 2 ). The number of assessments remained high and nurses felt that their work load was reduced and they were able to do proper assessments. Based on what they learnt during PDSA 2, the nurses suggested involving the patients and families to identify danger signs. One nurse per shift was assigned to educate new mothers and family members about danger signs and who to call if they needed help. The team ran a 4 week long PDSA (PDSA 3) to test how well the new room and patient education system worked.

\section{RESULTS}

During the PDSA 3, five $(1.6 \%)$ of 313 women who delivered were identified with complications, two of whom were identified by relatives. All the women were managed appropriately and discharged home. These changes also reduced the workload for the nurses, so the team implemented them permanently. Because the system was working and the complication data was more useful than the assessment data, the team stopped collecting assessment data. Between July and December $2014,74(2.2 \%)$ of the 3336 women who delivered were identified with complications (compared with $0.12 \%$ between January and May) (figure 1). There were no deaths on the postpartum ward in 2014 compared with five deaths in 2013. The system to identify women with complications was sustained and identified complications in $2.2 \%, 3.1 \%$ and $2.9 \%$ of all women who delivered in 2015, 2016 and 2017, respectively. In March 2015, the hospital was made a referral site by the government and the hospital started to receive sick patients from other hospital. After this change in case mix, the number of deaths increased. There were six, two and five deaths in 2015, 2016 and 2017, respectively.

\section{CONCLUSION}

To achieve their aim of improving postpartum assessment (ie, to increase the number of assessments and the number of women with complications identified) and reduce mortality, BMH used QI approaches to reorganise where women were placed in the postpartum ward and where assessment equipment was kept and to 
Table 1 Three plan-do-study-act (PDSA) cycles used to learn about the feasibility and effectiveness of setting up an observation room

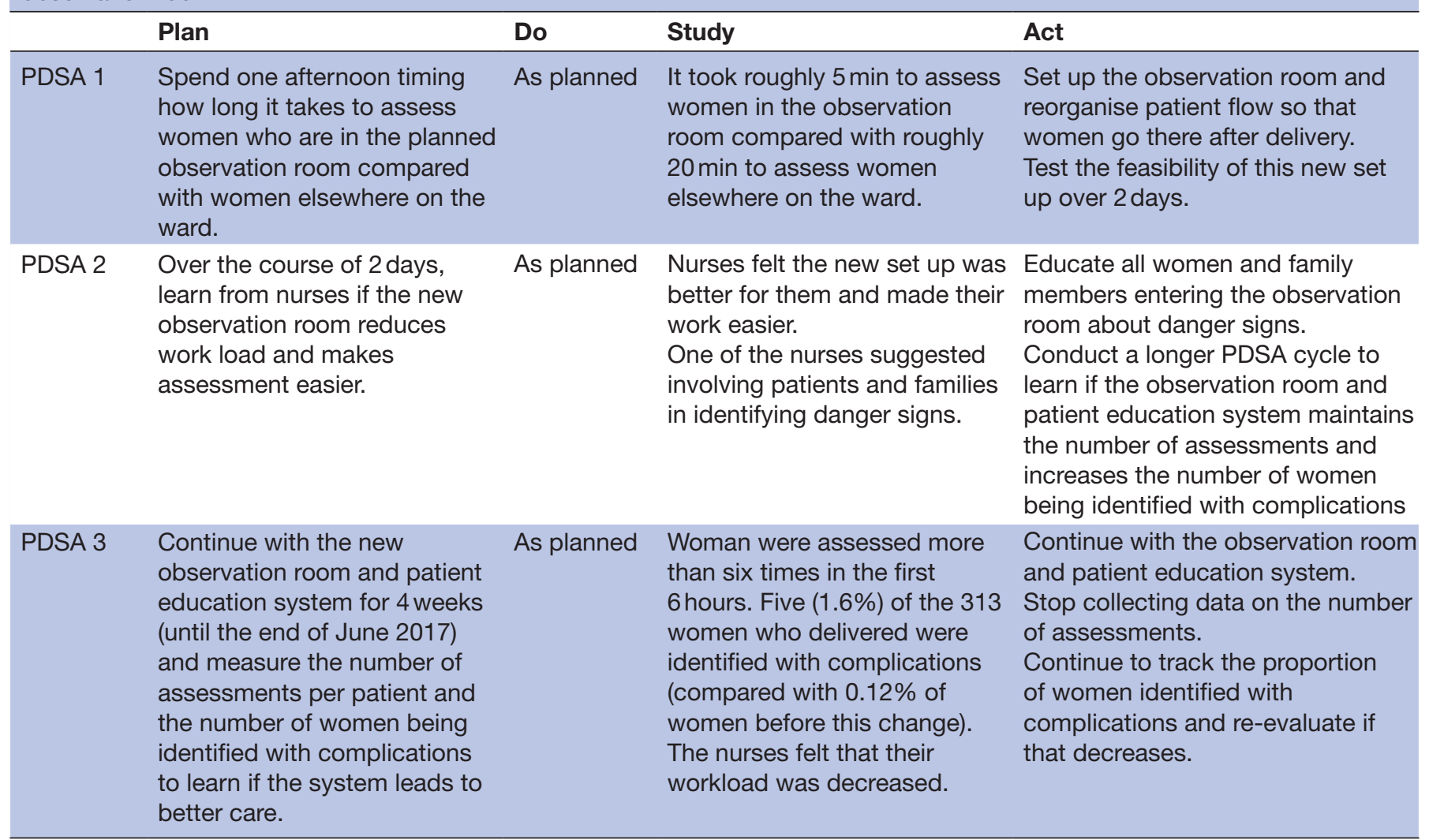

set up a system to educate women and families about when and how to call for help if they were worried about danger signs. These changes were adapted over three PDSA cycles and, when implemented, led to an increase in the number of women being identified with complications. This increase was sustained for over 3 years. Maternal mortality was reduced but this was not sustained after the hospital became a referral site. This was largely a function of the new case mix in patients but it also suggests the need for additional strategies to institutionalise the use of QI approaches for solving new problems.

The study's main limitation is the assessment data which captured the number of assessments but not the effectiveness of these assessments. Once the team had data showing assessment number was high and data on the number of complications being identified, they stopped recording assessment data as they felt it was no longer useful.

This report suggests that QI approaches can help improve care and reduce deaths but that more effort is required to institutionalise QI methods.

Acknowledgements We acknowledge the hard work and creativity of the staff who participated in the QI project.

Contributors All authors contributed to this paper. MC, NA, SS and NL planned the original QI project, adapted and implemented the project and collected data. SH drafted the paper with NL. All authors critically appraised, reviewed and approved the final version of the paper.
Funding The intervention described in this paper was made possible by the support of the American people through the United States Agency for International Development (USAID), through the USAID Applying Science to Strengthen and Improve Systems (ASSIST) Project, implemented by University Research Co., LLC under Cooperative Agreement Number AID-0AA-A-12-00101.

Competing interests None declared.

Patient consent Not required.

Provenance and peer review Not commissioned; internally peer reviewed.

Open access This is an open access article distributed in accordance with the Creative Commons Attribution Non Commercial (CC BY-NC 4.0) license, which permits others to distribute, remix, adapt, build upon this work non-commercially, and license their derivative works on different terms, provided the original work is properly cited, appropriate credit is given, any changes made indicated, and the use is non-commercial. See:Chttp://creativecommons.org/licenses/by-nc/4.0/.

\section{REFERENCES}

1. UN General Assembly. Transforming our world : the 2030 Agenda for Sustainable Development, 21 October 2015, A/RES/70/1.

2. Gülmezoglu AM, Lawrie TA, Hezelgrave N, et al. Interventions to reduce maternal and newborn morbidity and mortality. In: Black RE, Laxminarayan R, Temmerman M, eds. Reproductive, maternal, newborn, and child health: disease control priorities. 2. Third Edition. Washington (DC: The International Bank for Reconstruction and Development / The World Bank, 2016.

3. Austin A, Langer A, Salam RA, et al. Approaches to improve the quality of maternal and newborn health care: an overview of the evidence. Reprod Health 2014;11(Suppl 2):S1.

4. WHO, UNICEF, UNFPA, World Bank Group, and the United Nations Population Division. Trends in maternal mortality: 1990 to 2015. Geneva, World Health Organization. 2015 https://data.worldbank.org/ indicator/SH.STA.MMRT

5. Randive B, Diwan V, De Costa A. India's conditional cash transfer programme (the JSY) to promote institutional birth: is there an 
association between institutional birth proportion and maternal mortality? PLoS One 2013;8:e67452.

6. Ministry of Health and Family Welfare, Government of India.

Guidelines for pregnancy care and management of common obstetric complications by medical officers, 2005.
7. Singh $R$, Singh $M$, Jha R, et al. Improving quality in healthcare: a practical guide for health care providers. Technical report. Published by the USAID ASSIST Project. Bethesda, MD: University Research Co., LLC (URC). 2016 https://www.usaidassist.org/resources/ improving-quality-healthcare-practical-guide-health-care-providers 